\title{
A benchmarking of human mitochondrial DNA haplogroup classifiers from whole-genome and whole-exome sequence data
}

Víctor García-Olivares ${ }^{1}$, Adrián Muñoz-Barrera ${ }^{1}$, José Miguel Lorenzo-Salazar ${ }^{1}$, Carlos Zaragoza-Trello², Luis A. Rubio-Rodríguez ${ }^{1}$, Ana Díaz-de Usera' ${ }^{1}$, David Jáspez ${ }^{1}$, Antonio Iñigo Campos ${ }^{1}$, Rafaela GonzálezMontelongo $^{1,3}$, Carlos Flores $^{1,3,4,5}$

1. Genomics Division, Instituto Tecnológico y de Energías Renovables (ITER), Santa Cruz de Tenerife, Spain.

2. Estación Biológica de Doñana (EBD-CSIC), Integrative Ecology, E-41092 Sevilla, Spain.

3. Instituto de Tecnologías Biomédicas (ITB), Universidad de La Laguna, Santa Cruz de Tenerife, Spain.

4. Research Unit, Hospital Universitario Nuestra Señora de Candelaria, Universidad de La Laguna, Santa Cruz de Tenerife, Spain.

5. CIBER de Enfermedades Respiratorias, Instituto de Salud Carlos III, Madrid, Spain.

\footnotetext{
*Corresponding author: cflores@ull.edu.es
} 
bioRxiv preprint doi: https://doi org/10.1101/2021.02 11.430775. this version posted March 3 2021. The copyright holder for this preprint (which was not certified by peer review) is the author/funder, who has granted bioRxiv a license to display the preprint in perpetuity. It is made available under aCC-BY-NC-ND 4.0 International license.

\section{Abstract}

The mitochondrial genome (mtDNA) is of interest for a range of fields including evolutionary, forensic, and medical genetics. Human mitogenomes can be classified into evolutionary related haplogroups that provide ancestral information and pedigree relationships. Because of this and the advent of high-throughput sequencing (HTS) technology, there is a diversity of bioinformatic tools for haplogroup classification. We present a benchmarking of the 11 most salient tools for human mtDNA classification using empirical whole-genome (WGS) and whole-exome (WES) short-read sequencing data from 36 unrelated donors. Besides, because of its relevance, we also assess the best performing tool in third-generation long noisy read WGS data obtained with nanopore technology for a subset of the donors. We found that, for short-read WGS, most of the tools exhibit high accuracy for haplogroup classification irrespective of the input file used for the analysis. However, for shortread WES, Haplocheck and MixEmt were the most accurate tools. Based on the performance shown for WGS and WES, and the accompanying qualitative assessment, Haplocheck stands out as the most complete tool. For third-generation HTS data, we also showed that Haplocheck was able to accurately retrieve mtDNA haplogroups for all samples assessed, although only after following assembly-based approaches (either based on a referenced-based assembly or a hybrid de novo assembly). Taken together, our results provide guidance for researchers to select the most suitable tool to conduct the mtDNA analyses from HTS data.

Keywords: Mitogenome, lineage, third-generation sequencing, next-generation sequencing. 
bioRxiv preprint doi: https//doi.org/10.1101/2021.02 11.430775; this version posted March 3, 2021. The copyright holder for this preprint (which was not certified by peer review) is the author/funder, who has granted bioRxiv a license to display the preprint in perpetuity. It is made available under aCC-BY-NC-ND 4.0 International license.

\section{Introduction}

The human mtDNA is a circular double-stranded genome of 16,569 base pairs (bp) in the hg38 reference sequence, encoding 37 genes for 13 proteins, 22 tRNAs, and 2 rRNAs. Besides its key role in diverse human diseases (DeBalsi et al., 2017; Pyle et al., 2016; West \& Shadel, 2017), distinctive features such as the matrilineal inheritance, the lack of recombination, and a higher mutation rate than the nuclear genome, makes mtDNA analysis a powerful tool also for population genetics (Brotherton et al., 2013; Llamas et al., 2016; Posth et al., 2016) and forensic studies (Børsting \& Morling, 2015; Just et al., 2009).

Worldwide human mtDNA diversity has been reconstructed through a genealogy of distinctive lineages, representing mtDNA sequences clustered into evolutionarily related haplotypes (a.k.a. haplogroups). They are linked to human evolutionary history and allow tracing origins and differentiation patterns across populations and over time periods (Balter, 2011; Fu et al., 2013; Gonder et al., 2007; Hajdinjak et al., 2018). As such, many haplogroups are associated with specific biogeographical ancestries (Chan et al., 2019; De Angelis et al., 2018; Maca-Meyer et al., 2001). MtDNA haplogroup classification has become an essential step to recovery ancestry and genealogical information from analyzed samples (Weissensteiner et al., 2016). One of the most popular and continuously updated repositories of mtDNA lineage relationships and nomenclature is Phylotree (http://www.phylotree.org) (van Oven \& Kayser, 2009). The latest version of Phylotree (Build 17) contains more than 5,400 haplogroups and it constitutes the central reference for many bioinformatic tools to classify human mtDNA sequences.

The advent of high-throughput sequencing (HTS) technology has allowed the development of a wide range of applications, including whole-genome sequencing (WGS) and whole-exome sequencing (WES). MtDNA studies have also leveraged the power offered by HTS (Churchill et al., 2018; Schönberg et al., 2011; Vasta et al., 2009). In fact, mtDNA can be fully captured by commercial WES solutions, possibly due to the high copy number of mtDNA (Picardi \& Pesole, 2012). Hence, mtDNA information can be recovered effectively from WES studies at no extra cost. Furthermore, the sequencing depth associated with WES usually allows reconstructing the entire mitogenome with high quality and detecting heteroplasmic sites (Sosa et al., 2012). Third-generation HTS, such as those based on nanopore technology (ONT, Oxford Nanopore Technologies, Oxford, UK), allows sequencing with long reads, providing an opportunity to generate full-length mtDNA sequences in single reads.

Because of the importance of recovering ancestral information and pedigree relationships of study samples, the number of bioinformatics tools developed for mtDNA haplogroup classification has increased notably in the last decade to adapt to the HTS technologies (Calabrese et al., 2014; Fan \& Yao, 2011; Ishiya \& Ueda, 2017; Kim et al., 2020; Navarro-Gomez et al., 2015; Röck et al., 2013; Smieszek et al., 2018; Vohr et al., 2017; Weissensteiner et al., 2016, 2020). An unmet need is a benchmarking study of their capabilities, requirements, and usability to correctly classify the mtDNA haplogroups from different source files. Based on short-read WES and WGS data from the same donors, as well as on WGS obtained from long noisy reads from a subset of them, here we present an empirical evaluation of the 11 most salient bioinformatic tools available for human mtDNA classification from HTS data. 
bioRxiv preprint doi: https:/doi.org/10.1101/2021.02 11.430775. this version posted March 3,2021 . The copyright holder for this preprint (which was not certified by peer review) is the author/funder, who has granted bioRxiv a license to display the preprint in perpetuity. It is made available under aCC-BY-NC-ND 4.0 International license.

\section{Materials and methods}

Samples, library preparation and sequencing

The study was approved by the Research Ethics Committee of the Hospital Universitario Nuestra Señora de Candelaria and performed according to The Code of Ethics of the World Medical Association (Declaration of Helsinki).

Thirty-six DNA samples from unrelated donors of European descent were used for the study after informed consent (see supplementary Table S1). DNA was extracted from peripheral blood using a commercial column-based solution (GE Healthcare, Chicago, IL). DNA quantifications were performed in a Qubit dsDNA HS Assay (Thermo Fisher, Waltham, MA). All samples were sequenced in parallel using short-read WGS and WES. Library constructions were performed with Illumina preparation kits following the manufacturer's recommendations (Illumina Inc., San Diego, CA). The Nextera DNA Prep kit was used for WGS, except for six samples that were processed by Illumina DNA Prep. The same samples were processed with Nextera DNA Exome with a $350 \mathrm{bp}$ insert size as described elsewhere (Díaz-de Usera et al., 2020). The library quality control was carried out in a TapeStation 4200 (Agilent Technologies, Santa Clara, CA). Sequencing was conducted on a HiSeq 4000 Sequencing System (Illumina Inc.) at the Instituto Tecnológico y de Energías Renovables (Santa Cruz de Tenerife, Spain).

Eight of these samples had WGS based on noisy long-read data obtained at KeyGene (Wageningen, The Netherlands). Briefly, sequencing was performed on a PromethION system (ONT) for $64 \mathrm{~h}$ using one FLO_PR002 (R9.4.1 pore) flow cell per sample following the manufacturer's recommendations. Basecalling was performed on the PromethION computing module using MinKNOW v1.14.2 with Guppy v2.2.2 and data preprocessing was carried out with PycoQC (Leger \& Leonardi, 2019).

\section{Sequence processing and variant calling}

Processing of short-read WGS and WES data was carried out using an in-house pipeline (see supplementary Figure S1) based on GATK v4.1 for WGS and GATK v3.8 for WES (McKenna et al., 2010). Reads were aligned to the GRCh37/hg19 reference genome and the mtDNA reads realigned to the revised Cambridge Reference Sequence (rCRS), GenBank NC_012920 (Anderson et al., 1981; Andrews et al., 1999), following GATK best practices for this circular genome (see supplementary Figure S1). This required two alignment steps: one against the canonical mitogenome reference and another against the same reference but shifted by 8,000 nucleotide positions. This generates a displacement of the mtDNA D-loop to the opposite side of the contig, allowing to better capture variants of this highly variable region. The alignments were then processed for duplicate marking and base quality score recalibration (DePristo et al., 2011). The variant calls were obtained with the "mitochondria mode" of Mutect2 GATK v4.1. This specific mode provides a better sensitivity for this genome as it shows a robust detection of very low fractions of variants once the nuclear mtDNA segments (NuMT) are filtered out. The mtDNA variants were then filtered by using FilterMutectCalls and VariantFiltration tools to keep the variants classified as PASS. 
bioRxiv preprint doi: https://doi org/101101/2021.02 11.430775; this version posted March 3,2021 . The copyright holder for this preprint (which was not certified by peer review) is the author/funder, who has granted bioRxiv a license to display the preprint in perpetuity. It is made available under aCC-BY-NC-ND 4.0 International license.

For ONT data, we first extracted all reads aligning to the mtDNA genome and then used four alternative strategies to obtain sequence variation for mtDNA classification: a) one based on the alignment of reads to the rCRS sequence with Minimap2 (Li, 2018) followed by a variant-calling step with Medaka (https://github.com/nanoporetech/medaka); b) another relying on the reference-based assembly performed by Rebaler (https://github.com/rrwick/Rebaler); c) a third strategy based on de novo assembly with Miniasm (Li, 2016) followed by nine rounds of polishing with Racon (Vaser et al., 2017) and a final step with RagTag (Alonge et al., 2019) for scaffolding; and d) the last strategy combining ONT and Illumina reads in a hybrid de novo assembly built with Unicycler (Wick et al., 2017) and a final step with RagTag for scaffolding (see supplementary Figure S2). Quality of assemblies were assessed with QUAST (Gurevich et al., 2013). For all the alternatives, a VCF file per sample was generated for the haplogroup classification step.

For each sample, three different files were generated for short-read data: BAM and VCF files created through the pipeline previously described, and FASTA files obtained by the VCF-consensus script included in vcftools (Danecek et al., 2011) generated from the VCF files. Of note, an additional filter was applied to the VCF files discarding variants that showed an allele fraction below 0.9, a threshold applied by default in Haplogrep during the haplogroup classification. This enabled the harmonization of the genetic variation considered in FASTA and VCF files.

\section{mtDNA haplogroup classification}

Among the tools available from the literature, we selected 11 that were published in the last three years or that were cited at least 30 times since its description (Table 1). Haplogrep, Haplocheck and Phy-Mer have the option of using alternative input files, fostering an evaluation with the alternative supported format files. Some of the tools provide quality scores supporting the mtDNA haplogroup classification. In these cases, only the classification with the best scoring was considered for the analyses. For the haplogroup classification process, the tools that were designed to be run locally, either through an application or via command line, were executed on a 4-core Intel Core i7 CPU at $2.6 \mathrm{GHz}$ and $16 \mathrm{~GB}$ of RAM.

Table 1. List of software assessed for human mtDNA haplogroup classification. All the tools assessed classify mtDNA sequences according to the PhyloTree nomenclature by using the latest version Build 17. Two of them, MitoTool and PhyMer, remain outdated in regards of the PhyloTree built when this study was conducted.

\begin{tabular}{|c|c|c|c|c|c|c|c|}
\hline Tool & $\begin{array}{c}\text { User } \\
\text { interface }\end{array}$ & $\begin{array}{c}\text { Release } \\
\text { year }\end{array}$ & Version & $\begin{array}{l}\text { Latest } \\
\text { release }\end{array}$ & $\begin{array}{c}\text { Database } \\
\text { version }\end{array}$ & $\begin{array}{l}\text { Input } \\
\text { options }\end{array}$ & $\begin{array}{c}\text { Execution time }^{\$} \\
\text { (seconds) }\end{array}$ \\
\hline James Lick'sa & Web & 2010 & $0.19 a$ & 2013.04.08 & Phylotree 17 & FASTA & $20-27$ \\
\hline Haplogrep ${ }^{b}$ & Web / CLI* & 2011 & 2.2 .4 & 2016.07 .08 & Phylotree 17 & VCF | FASTA & $0.1 \mid 1-3$ \\
\hline MitoTool' & App & 2011 & 1.1 .2 & 2013.11.02 & Phylotree 16 & FASTA & $2-3$ \\
\hline Haplofind $^{d}$ & Web & 2013 & - & 2013.01.12 & Phylotree 17 & FASTA & $11-15$ \\
\hline $\mathrm{EMMA}^{\mathrm{e}}$ & Web & 2013 & 13 & 2019.11.28 & Phylotree 17 & FASTA & $10-38$ \\
\hline Phy-Merf & Web / CLI* & 2015 & 1.0 .0 & 2016.01.14 & Phylotree 16 & BAM | FASTA & $8-298 \mid 51-54$ \\
\hline MitoSuite ${ }^{g}$ & App & 2017 & 1.0 .9 & 2017.06 .06 & Phylotree 17 & BAM & $10-340$ \\
\hline MixEmt ${ }^{h}$ & $\mathrm{CLI}$ & 2017 & 0.1 & 2017.05.09 & Phylotree 17 & BAM & $79-5034$ \\
\hline Haplocheck & Web / CLI* & 2019 & 1.1 .0 & 2019.11.17 & Phylotree 17 & BAM | VCF & $3-14 \mid 1-2$ \\
\hline Haplotracker ${ }^{j}$ & Web & 2020 & - & 2020.04 .23 & Phylotree 17 & FASTA & $30-32$ \\
\hline HaploGrouperk & $\mathrm{CLI}$ & 2020 & - & 2020.08 .17 & Phylotree 17 & VCF & 0.1 \\
\hline
\end{tabular}


bioRxiv preprint doi: https://doi org/10.1101/2021.02 11.430775; this version posted March 3, 2021. The copyright holder for this preprint (which was not certified by peer review) is the author/funder, who has granted bioRxiv a license to display the preprint in perpetuity. It is made available under aCC-BY-NC-ND 4.0 International license.

a: https://dna.jameslick.com/mthap/; b: (Weissensteiner et al., 2016); c: (Fan \& Yao, 2011, 2013); d: (Vianello et al., 2013); e: (Röck et al., 2013); f: (NavarroGomez et al., 2015) ; g: (Ishiva \& Ueda, 2017); h: (Vohr et al., 2017); i: (Weissensteiner et al., 2020); j: (Kim et al., 2020); k: (Jagadeesan et al., 2020).

\section{Statistical analyses}

All statistical analyses were performed in R v.3.3.3 (R Core Team 2017). Model fitting was evaluated visually using the 'DHARMa' package (Hartig, 2017) (v.0.1.5). Prior to analysis, all predictors were standardized by subtracting the mean and dividing by the standard deviation with the 'scale' base function in R.

In order to evaluate the performance of the 11 tools in the classification, we ran generalized linear mixed models (GLMM) with the tools as fixed factor and the classification results (concordance/discordance) as the response variable. This was done separately for WGS and WES data. In the models, we included the sample as a random factor to account for differences introduced by the sequencing runs and the diverse enrichment kits involved. Classification results were transformed to a binary response so that, for each sample, discordance between the consensus haplogroup and the classification result was coded as one, and the concordance as zero. In such binary outcome data, the models may suffer from complete separation when one of the levels of an explanatory variable explains completely the binomial response variable, precluding an optimal fitting of the algorithm (Heinze \& Schemper, 2002). This prevents the algorithm from properly fitting the coefficient for this level. To overcome this issue, we fitted the models using the bglmer function of the "blme" v.1.0.4 R package (Chung et al., 2013), which incorporates a similar algorithm to "Imer4" v.1.1.15 R package (Bates et al., 2015) to facilitate the estimation with the incorporation of a prior. Before the analysis, a Pearson's correlation test was conducted to examine the cross-correlation among the different sequencing parameters measured (i.e., mapped reads, duplicate reads, depth, mean mapping quality, and base quality). Pearson's correlation test revealed that the proportion of duplicate reads and the depth of coverage were highly correlated $(r<0.8)$. Therefore, only the mapped reads, mapping quality, and base quality were incorporated as covariates in the model (see supplementary Table S2). Finally, to evidence the pairwise differences between the tools, we run a post-hoc analysis with the Tukey contrast by using the "multcomp" v.1.4.8 package (Hothorn et al., 2008). Model outputs were visualized using 'effects' v.0.9.4 (Fox, 2003) and 'ggplot2' v.2.2.1 (Wickham, 2016).

\section{Results}

\section{Short-read sequencing summary of mitogenomes}

The mean $( \pm S D)$ number of mtDNA reads recovered per sample $(n=36)$ for short-read WGS and WES data were $197,717 \pm 98,719$ and $9,905 \pm 6,808$, respectively. For WGS, $100 \%$ of the mitogenome was covered at least at $1 X$. For WES, this percentage decreased to a mean ( \pm SD) of $86.79 \% \pm 27.01$ of the recovered mitogenome. The mean ( \pm SD) mapping quality for mapped reads had a value of $59.9 \pm 0.01$ and the Phred base-quality scores estimated were high for both applications ( $28.38 \pm 0.91$ for WGS, and $29.74 \pm 0.02$ for WES). The average ( \pm SD) depth recovered for WGS was 1,119X \pm 433 (range: 554-2,577X), decreasing to 37X \pm 20 for WES (range: 11-92X). Besides, while WGS provided a homogeneous depth of coverage profile across the mitogenomes, those 
bioRxiv preprint doi: https:/doi org/10.1101/2021.02 11.430775. this version posted March 3,2021 . The copyright holder for this preprint (which was not certified by peer review) is the author/funder, who has granted bioRxiv a license to display the preprint in perpetuity. It is made available under aCC-BY-NC-ND 4.0 International license.

recovered by WES showed a highly heterogeneous profile across samples. Interestingly, the region between nucleotide positions 2,000-3,000 was highly enriched in reads from Illumina WES data (Figure 1). As for the number of detected variants after filtering, the mean $( \pm S D)$ depth of coverage per variant call had a value of 958 \pm 362 in WGS, decreasing to $40 \pm 21$ in WES. Out of the 36 samples sequenced, ten showed the equivalent number of variants by WGS and WES. In the remaining samples, the number of variants detected by WES was lower than by WGS: 17 samples missed between 1 and 3 variants, and nine missed more than $30 \%$ of the variants (Table S1).

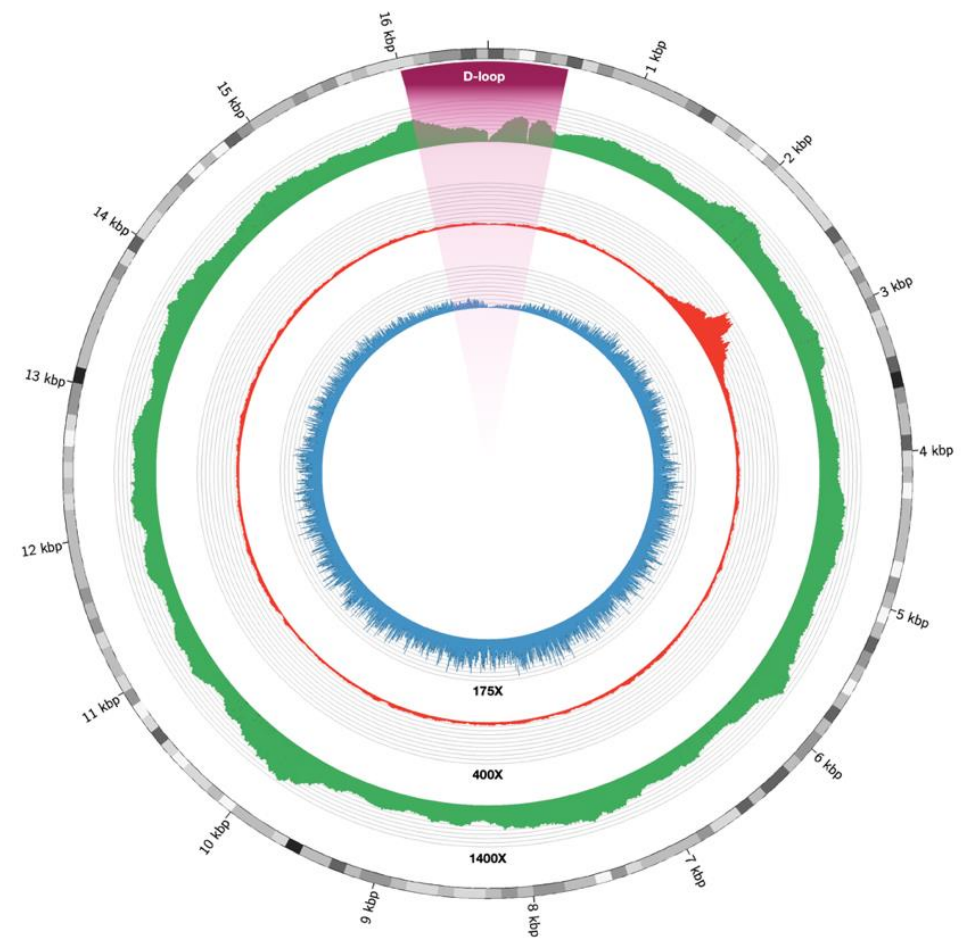

Figure 1. Circos plot of the depth of coverage for short-read and long-read sequencing in the mtDNA of an exemplar sample. Short-read WGS and WES data are colored in green and red, respectively. Long-read WGS data is shown in blue.

\section{Haplogroup classification based on short-read data}

Twenty-eight samples showed $>90 \%$ concordance in the haplogroup classification among the 11 tools. The remaining showed a mean concordance rate of $69.23 \%$ (see supplementary Table S3). In addition, a higher classification accuracy was provided for WGS, reaching an average of $90.08 \%$, while for WES it decreased to an average of $76.98 \%$ (see supplementary Table S4). On average $( \pm$ SD), there were more discordances on the WES classifications $(2.97 \pm 3.92)$ than for WGS $(1.39 \pm 1.48)$. Based on this evidence, we set the WGS-derived haplogroup as the ground truth.

By the classification accuracy, Haplogrep, Haplocheck, EMMA, and James Lick's mtHap classified all samples correctly based on WGS. For the WES data, only Haplocheck classified all haplogroups correctly, and only when the BAM file was used as input. Concerning the less accurate classifiers, MixEmt showed the lowest accuracy for WGS, only classifying precisely $30.55 \%$ of the analyzed samples. MitoTool was the least accurate tool for WES data, yielding an incorrect haplogroup classification in $41.67 \%$ of the samples. The execution time required for haplogroup classification was also very different between the tools (Table 1). As expected, 
bioRxiv preprint doi: https://doi.org/10.1101/2021.02 11.430775. this version posted March 3, 2021. The copyright holder for this preprint (which was not certified by peer review) is the author/funder, who has granted bioRxiv a license to display the preprint in perpetuity. It is made available under aCC-BY-NC-ND 4.0 International license.

classifications that relied on BAM inputs had a processing time higher than those running with FASTA and VCF files. Among the tools that support BAM file inputs, MixEmt was the most time-consuming, in which the heterogeneity of processing time among samples was likely due to the different number of mtDNA reads between datasets. In case of Haplocheck, which was designed along with MixEmt to estimate the potential crosscontamination of samples, it required less time per sample for the haplogroup classification.

\section{Modelling of the haplogroup classification accuracy}

Based on these results, we modelled the performance of the 11 tools for short-read mtDNA data classification. The total variance explained by a fixed effects model was $57.69 \%$ and $46.19 \%$ for WGS and WES data, respectively. The predicted probabilities were then estimated in order to assess the haplogroup classification accuracy of each tool both on WES and WGS data (Figure 2). Among all tools, MixEmt (estimate \pm SE; $3.55 \pm 0.66$; $p<0.001)$ was the one with the lowest accuracy in correctly classifying the haplogroup from WGS $(80.91 \%$ predicted probability of incorrect classification). The rest of the tools showed a negligible probability of misclassifying the haplogroup from WGS (Figure 2 and Table S5). Post-hoc tests did not show statistically significant differences among them. For WES, Haplocheck $(-4.38, \pm 1.99, p=0.03)$ and MixEmt $(-1.13, \pm 0.50, p$ $=0.02$ ), both using BAM as the input file, were the tools showing the highest accuracy for haplogroup classification (Figure 2 and Table S5). Haplocheck correctly classified the haplogroup for all samples, while MixEmt incorrectly classified four of the 36 samples analyzed. Despite that, post-hoc tests did not show significant differences in the classification performance between Haplocheck and MixEmt. On the contrary, MitoTool $(0.97, \pm 0.49, p=0.05)$ showed the lowest accuracy in the haplogroup classification based on WES, for which the predicted probability of incorrectly classifying an haplogroup was $\geq 25 \%$. Regarding the effect of the covariates, their effect was negligible for WGS data. However, for the WES data, a relatively high effect size was found for the mapped reads $(-5.96 \pm 3.55 ; p=0.09)$ and the mapping quality $(1.16 \pm 0.39 ; p<0.001)$ (Table S5). Taken together, these results suggest that the number of reads available and their mapping quality have stronger effects on the probability of inaccurate haplogroup classification based on WES data than based on WGS data.

a)

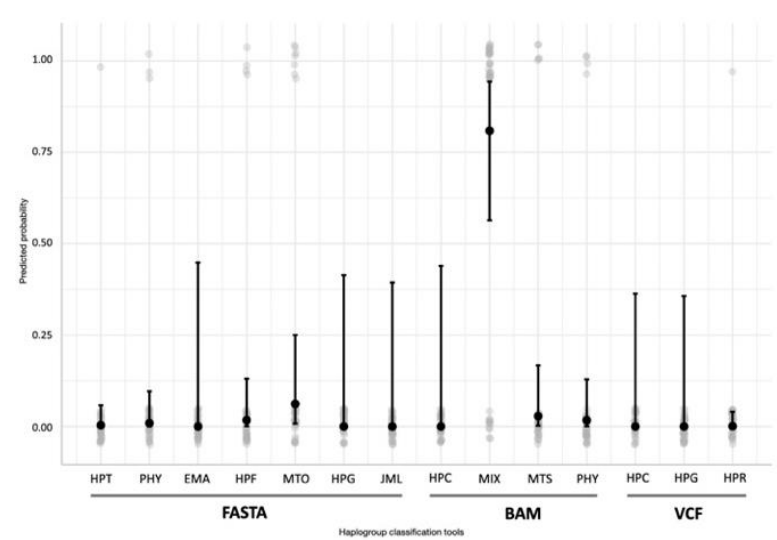

b)

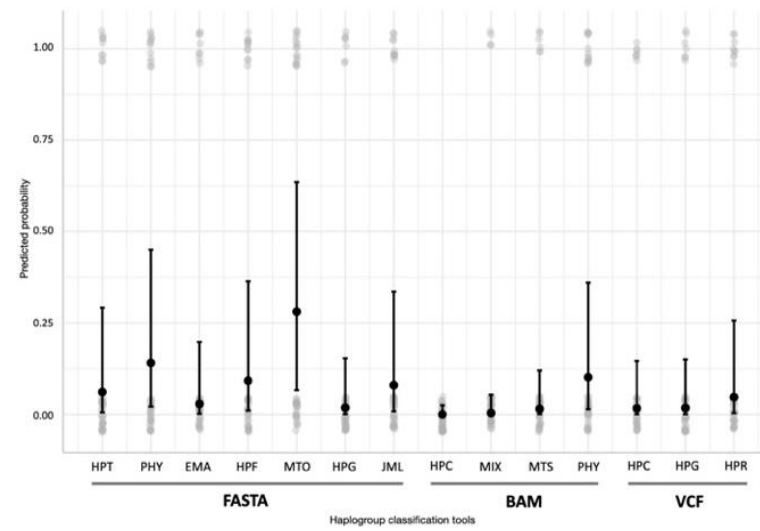

Figure 2. Predicted probability values (and 95\% confidence intervals) of the GLMM model estimated for each tool for a) WGS and b) WES datasets. In light grey, the raw data from the haplogroup classification results.

JML: James Lick's, HPG: Haplogrep, MTO: MitoTool, HPF: Haplofind, EMA: EMMA, PHY: Phy-Mer, MTS: MitoSuite, MIX: MixEmt, HPC: Haplocheck, HPT: Haplotracker, HPR: HaploGrouper. 
bioRxiv preprint doi: https://doi.org/10.1101/2021.02.11.430775; this version posted March 3, 2021. The copyright holder for this preprint (which was not certified by peer review) is the author/funder, who has granted bioRxiv a license to display the preprint in perpetuity. It is made available under aCC-BY-NC-ND 4.0 International license.

\section{Qualitative assessment of haplogroup classification tools}

Due to the large number of haplogroup classification tools, a secondary aim of this study was to provide a guidance for researchers to select the most suitable tool for their analyses, not only based on the mtDNA haplogroup classification accuracy but also based on different software features and the usability of the evaluated tools. In order to facilitate the comparison among different tools, a qualitative assessment table is provided with the advantages and limitations of each tool. For this, the following characteristics were considered: haplogroup classification accuracy, computation time for classification, whether or not the latest Phylotree database is used, ability to process cohorts, versatility in the input files supported, user-friendly interface, frequency of tool maintenance, and the presence of others major functions (Table 2). Overall, Haplocheck proved to be the most complete tool, achieving the best performance in over $90 \%$ of the evaluated features. At the opposite end, Phy-Mer, with more than $50 \%$ of the features resulting poorly classified was the tool with the worst performance among all the assessed tools in this study.

Table 2. Qualitative assessment of mtDNA haplogroup classification tools. Performance of each tool is evaluated across different features and represented on a color scale based on the level of performance: green for good, orange for fair, and red for low performance.

Haplogroup classification accuracy of each tool was categorized into three ranges based on the predicted probabilities by each application: tools with a predicted probability of incorrectly classifying a haplogroup below $1 \%$ were represented as good performance, for a fair performance was established a range between $1.01 \%$ and $10 \%$, and as low performance tools with a predicted probability higher than $10.01 \%$. For computation time, three intervals were established: tools that classified samples in less than a minute were defined as good performance, from 1 to 5 minutes were categorized as fair performance, and those tools that required more than an hour were represented as low performance. Regarding the PhyloTree database used, it was represented as low performance those tools which are not updated to the latest version of Phylotree, Build 17, and those that allow the latest version as high performance. Multi-sample function was evaluated based on the possibility of cohort analysis. Tools that allow to process these functions were defined as good performance, tools that allow processing several samples by using a loop through a command-line were categorized as fair performance, and tools without this ability were represented as low performance. Based on the file format supported two categories were established: tools that support various input format files categorized as high performance and those that only support one format file that are represented as low performance. The user interface was divided into two categories, tools based on web or desktop applications defined as good performance, and tools developed exclusively for CLI as low performance. The tool maintenance was classified into two classes, tools updated continually or have been recently released, both identified as good performance, and tools that have not been updated during the last years. The last feature is the presence or not of additional functions; tools that have other functions implemented are categorized as good performance. Those tools without more functions were determined as low performance.

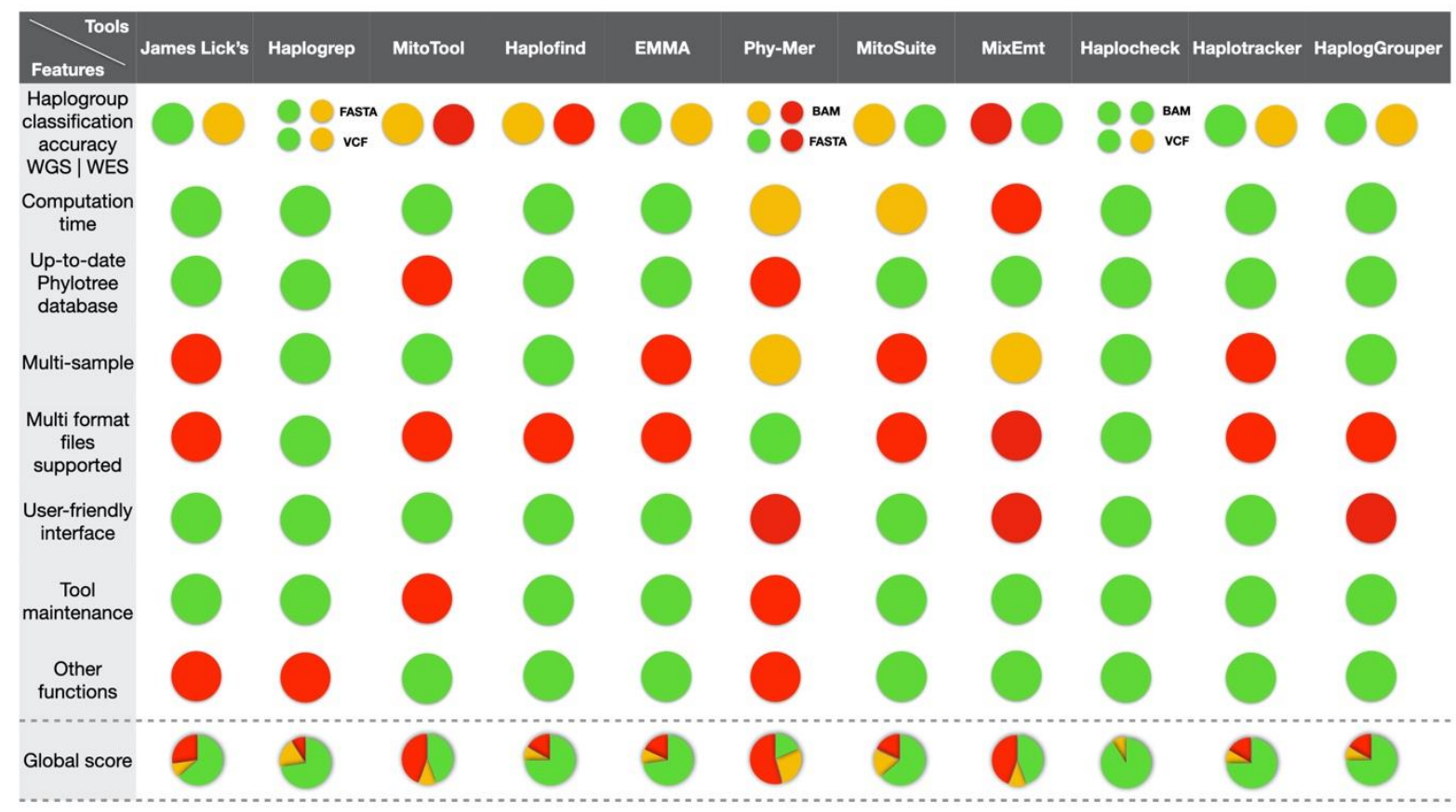


bioRxiv preprint doi: https://doi org/101101/2021.02 11 430775; this version posted March 3,2021 . The copyright holder for this preprint (which was not certified by peer review) is the author/funder, who has granted bioRxiv a license to display the preprint in perpetuity. It is made available under aCC-BY-NC-ND 4.0 International license.

\section{Assessment of ONT data for mtDNA haplogroup classification}

The mean $( \pm S D)$ number of mtDNA reads per sample $(n=8)$ recovered by ONT was $2,812 \pm 1,003$. The average mtDNA coverage depth was 576X (range: 358-910X). The ONT-recovered mitogenome profile was uniform. However, a decrease in the coverage depth was observed for the D-loop region (positions between 16,024-576) (Figure 1). Regarding the quality of the recovered assemblies, the hybrid de novo and reference-based assembly strategies reached a similar value of N50, with 16,571 bp and 16,569 bp, respectively. However, for the longread only de novo assembly, this length decreased to $16,407 \mathrm{bp}$. The consensus overall identity with the rCRS sequence reached a value of $100 \%$ for hybrid de novo assembly, $99.97 \%$ for reference-based strategy, and $88.99 \%$ for the long-read only de novo assembly strategy. Taking the called variants by short-read WGS as the ground truth, the variant calling strategy for ONT data shared a consensus average $( \pm S D)$ of $76.41 \%( \pm 5.43)$, the reference-based assembly shared an average of $93.95 \%$ ( \pm 5.76 ), de novo assembly shared an average of $89.13 \%$ ( \pm 5.56$)$, and the hybrid de novo assembly shared an average of $97.35 \%( \pm 3.34)$. In addition, the strategies that only use ONT reads for mtDNA assembly called a larger number of variants that were undetected by short-read WGS. The reference-based assembly strategy called a total of 61 ( \pm 31 ) variants and de novo assembly 158 ( \pm 173). For the variant calling and hybrid de novo assembly strategies, the number of novel variants called was lower, decreasing to an average of $3( \pm 2)$ and $1( \pm 2)$, respectively.

Given that Haplocheck was the best performing classifier based on short-read data, we then used it for ONT mtDNA haplogroup classification. The reference-based assembly and the hybrid de novo assembly strategies classified all samples correctly. However, both the variant calling and the de novo assembly approaches incorrectly classified one out of the eight samples analyzed. Despite that, all samples were classified correctly at the macro-haplogroup level with all strategies (Table 3).

Table 3. Long-read (ONT) sequencing summary and haplogroup classification results for the samples. The results of the shortread whole-genome sequencing (WGS) mtDNA classification are also shown.

\begin{tabular}{|c|c|c|c|c|c|c|c|c|c|c|c|c|}
\hline \multirow{2}{*}{ Samples } & \multicolumn{2}{|c|}{$\begin{array}{c}\text { ONT } \\
\text { sequencing }\end{array}$} & \multicolumn{2}{|c|}{$\begin{array}{l}\text { Variant- } \\
\text { calling }\end{array}$} & \multicolumn{2}{|c|}{$\begin{array}{c}\text { Reference-based } \\
\text { assembly }\end{array}$} & \multicolumn{2}{|c|}{$\begin{array}{l}\text { De novo } \\
\text { assembly }\end{array}$} & \multicolumn{2}{|c|}{$\begin{array}{c}\text { Hybrid de novo } \\
\text { assembly }\end{array}$} & \multicolumn{2}{|c|}{$\begin{array}{c}\text { Short-read } \\
\text { WGS }\end{array}$} \\
\hline & $\begin{array}{c}\text { Mapped } \\
\text { reads }\end{array}$ & $\begin{array}{l}\text { Depth of } \\
\text { coverage }\end{array}$ & Variants & Haplogroup & Variants & Haplogroup & Variants & Haplogroup & Variants & Haplogroup & Variants & Haplogroup \\
\hline CAN03 & 3,065 & 581 & 14 & H1ao1 & 69 & H1ao1 & 119 & H1ao1 & 16 & H1ao1 & 14 & H1ao1 \\
\hline CANO6 & 2,981 & 566 & 36 & $J 2 a 2 d$ & 141 & $J 2 a 2 d$ & 154 & $J 2 a 2 d$ & 46 & $J 2 a 2 d$ & 44 & $J 2 a 2 d$ \\
\hline CANO7 & 2,343 & 444 & 15 & H6a1b2 & 132 & H6a1b2 & 175 & H6a1b & 17 & H6a1b2 & 14 & H6a1b2 \\
\hline CANO9 & 2,126 & 358 & 33 & U4c1 & 66 & U4c1 & 602 & U4c1 & 37 & U4c1 & 37 & U4c1 \\
\hline CAN17 & 4,209 & 821 & 10 & $\mathrm{H} 2 \mathrm{a} 2$ & 59 & $H+16189$ & 41 & $H+16189$ & 15 & $H+16189$ & 12 & $H+16189$ \\
\hline CAN23 & 1,737 & 532 & 29 & K1a1b1 & 69 & K1a1b1 & 78 & K1a1b1 & 37 & K1a1b1 & 35 & K1a1b1 \\
\hline CAN31 & 1,776 & 398 & 20 & U6b1a1 & 67 & U6b1a1 & 119 & U6b1a1 & 28 & U6b1a1 & 26 & U6b1a1 \\
\hline CAN34 & 4,256 & 910 & 34 & L3f1b1a & 90 & L3f1b1a & 174 & L3f1b1a & 42 & L3f1b1a & 43 & L3f1b1a \\
\hline
\end{tabular}


bioRxiv preprint doi: https://doi.org/10.1101/2021.02 11.430775; this version posted March 3, 2021. The copyright holder for this preprint (which was not certified by peer review) is the author/funder, who has granted bioRxiv a license to display the preprint in perpetuity. It is made available under aCC-BY-NC-ND 4.0 International license.

\section{Discussion}

Over the last decade, the number of mtDNA haplogroup classification tools has increased considerably. However, to our best understanding, there was no benchmarking study that assessed the accuracy of the haplogroup classification provided by them until now. This study presents a comparative of the 11 tools that are most widely used. The evaluation was done using empirical HTS data from two of the most widely used applications in human genetics, WES and WGS, in diverse empirical data. Besides, we also evaluated the best performing tool in long noisy ONT reads in a subset of the samples. Our results support that WES offers a suitable solution to allow accurate reconstruction of the mtDNA sequence, although at a lower depth of coverage than WGS. Our results also demonstrated that the most accurate tools for human mtDNA haplogroup classification from short-read WGS data are Haplogrep, Haplocheck, James Lick's, EMMA, HaploGrouper, and Haplotracker. On the contrary, for short-read WES, Haplocheck and MixEmt were the most accurate. Considering both the accuracy of classification for both approaches and the qualitative assessment made, Haplocheck demonstrated the best performance overall. In fact, using Haplocheck on long noisy ONT reads, we were able to accurately retrieve the mtDNA haplogroup from all assessed samples.

Previous studies have used WES data for human mitogenome reconstruction (Griffin et al., 2014; Patowary et al., 2017; Picardi \& Pesole, 2012; Wortmann et al., 2015). Based on our comparisons between WGS and WES datasets, the most striking difference between their classification results was mainly related to the breadth and depth of coverage, both being better for WGS than for WES under our standards. Differences in mtDNA breadth of coverage were less pronounced. However, the mean depth of mtDNA for WGS was around 30 times higher than that obtained by WES. For WGS, the depth reported in diverse studies ranged between 1,200-4,000X (Puttick et al., 2019; Raymond et al., 2018; Watson et al., 2020), fitting with the expected proportion of mtDNA copy number compared to the nuclear DNA, which theoretically differs by 10 to 100 times (Al-Nakeeb et al., 2017; Robin \& Wong, 1988). With respect to WES, the observed depth fits in the range described in the literature (Abicht et al., 2018; Diroma et al., 2020; Griffin et al., 2014; Patowary et al., 2017). Attending to the number of variants compared to those detected by WGS, a loss of variants was observed for WES in several samples. This may be explained by the low number of mapped reads of the mtDNA recovered in these samples, causing a shallower mtDNA depth. Despite that, based on the BAM-deduced haplogroup results, we and others (Diroma et al., 2020) have confirmed that WES can be an efficient approach to recover complete human mitogenomes, which allows retrieving the haplogroup with comparable accuracy to that based on WGS.

In general, a loss of accuracy in mtDNA classification was found for WES data in most of the evaluated tools. This could be explained by the lower depth of mitogenomes in WES compared to WGS, as has been described elsewhere (Ishiya \& Ueda, 2019; Yin et al., 2019), given that a low depth of coverage will have negative consequences on the performance of the variant calling algorithms (Jennings et al., 2017; Petrackova et al., 2019). mtDNA haplogroup classification relies on a hierarchical algorithm based on the presence or absence of specific diagnostic variants defining the genealogy (Lee et al., 2008). Therefore, missing key variants due to the low depth may have a strong impact on the correct assignment in those tools that only support VCF and/or FASTA files as input. In contrast, the tools that can rely on BAM as an input file, given that this format contains all mapped reads -- including information about the alignment conditions and the complete sequence together 
bioRxiv preprint doi: https://doi.org/10.1101/2021.02 11.430775; this version posted March 3, 2021. The copyright holder for this preprint (which was not certified by peer review) is the author/funder, who has granted bioRxiv a license to display the preprint in perpetuity. It is made available under aCC-BY-NC-ND 4.0 International license.

with the quality for each base -- may facilitate the proper haplogroup classification in sample datasets where certain variant positions are supported by a low number of reads. Hence, the BAM format might be optimal in samples where a low number of mtDNA reads is expected. The use of the BAM file as a possible input file for haplogroup classification has become popular in the last few years (Ishiya \& Ueda, 2017; Navarro-Gomez et al., 2015; Vohr et al., 2017; Weissensteiner et al., 2020). With respect to the WES haplogroup results, the tools that support BAM as input files obtained the highest classification accuracy, except Phy-Mer, which was one of the tools performing worst in the classification. Haplocheck and MixEmt reached the highest accuracy among all the tools evaluated. Haplocheck excels in the correct classification of all samples, even with low depth of mtDNA, unlike MixEmt, which resulted in several misclassifications. On the other hand, our results from WES data also showed that the total number of mapped reads, which closely relates to the depth of coverage, has a strong effect on the haplogroup classification, affecting the classification of the samples with a low number of mtDNA reads. However, the effect of this variable was negligible in WGS datasets. Consequently, the total number of mtDNA mapped reads can be considered another key factor to take into account in the mtDNA classification from WES datasets.

Haplogrep, Haplocheck, James Lick's, EMMA, HaploGrouper, and Haplotracker tools yielded the highest accuracy scores based on WGS data, and their accuracy was independent of the input file format. This finding may be related to the high and uniform depth of WGS throughout the mitogenome, translating in strong support of variants by a high number of reads and, therefore, making more equivalent the information contained in the BAM, VCF, and FASTA files. Haplogrep and Haplocheck, both sharing the underlying algorithm developed first for Haplogrep and now integrated as a module directly in Haplocheck (Weissensteiner et al., 2020), were the ones providing the best ratings for all evaluated features. Despite that, taking into account all the evaluated features, Haplocheck stands out as the most complete haplogroup classification tool for WGS data as it also allows detecting potential sample contaminations based on BAM files. For those users who prefer working with mtDNA alignments in FASTA format and with the sole objective of classifying a limited number of samples by web-based user-friendly tools, EMMA, James Lick's, HaploGrouper, and Haplotracker are good choices as they all showed similar accuracies as Haplogrep and Haplocheck. EMMA is integrated into the EMPOP platform and stands out as one of the most complete and up-to-date databases of human mtDNA information, containing high quality representations of haplogroups from all over the world based on logical and phylogenetic measures suitable for forensic purposes (Amorim et al., 2019; W. Parson et al., 2014). James Lick's is one of the first tools released for mitochondrial haplogroup classification that is continually updated to new versions of the PhyloTree database. This tool is widely used among genetic genealogists because it is user friendly and based on a web application. HaploGrouper, the most recently released tool, allows classifying the haplogroups both for mtDNA and the non-recombining portion of the Y-chromosome, being unique in this dual function. However, this tool requires basic bioinformatic skills since it runs from a command-line interface. Finally, Haplotracker has been designed for fragmented DNA samples, such as degraded ones, allowing datasets to be classified using both short reads and complete mtDNA sequences. It runs as a web application with a user-friendly interface that makes it appealing for users without bioinformatics skills. 
bioRxiv preprint doi: https://doi org/10.1101/2021.02 11.430775; this version posted March 3, 2021. The copyright holder for this preprint (which was not certified by peer review) is the author/funder, who has granted bioRxiv a license to display the preprint in perpetuity. It is made available under aCC-BY-NC-ND 4.0 International license.

Long-read sequencing technology allows new genome discoveries leveraging the improvements in genome assemblies and detecting structural variants, among others. Long noisy ONT reads have been applied for studies of the nuclear genome (Beyter et al., 2019; Olson et al., 2020). However, there are few examples of the use of this sequencing technology for mtDNA genome analysis (Franco-Sierra \& Díaz-Nieto, 2020; Lindberg et al., 2016). The Achilles' heel of this emerging sequencing technology, the high error rates, is continuously improving mostly based on pore modifications and the development of basecalling methods. Here we showed that reference-based assembly and hybrid de novo assembly strategies provide precise results for haplogroup classification. However, despite the high number of artefactual variants detected using only the long reads for assemblies (reference-based and de novo), these results could be improved using new methods for basecalling and/or genome assembly. Irrespective of that, our results demonstrate that the ONT reads are appropriate for recovering accurate mtDNA haplogroups from WGS data.

\section{Conclusions}

With the advent of the HTS technologies, the number of human mtDNA haplogroup classification tools has increased notably in the last decade. Each new tool released incorporates novel features and different analysis functions, but this has not been always linked to an improvement in the haplogroup classification accuracy. In this study, an evidence-based benchmarking effort was proposed to compare the classification accuracy provided by the most salient tools. We conclude that Haplocheck is the most suitable mtDNA haplogroup estimator for WGS and WES datasets, not only because of its classification accuracy but also because of all the included features and its user-friendly web interface. Regarding third-generation HTS, despite the lower per base accuracy currently offered by ONT, we found that it does not hinder a precise human mtDNA classification. 
bioRxiv preprint doi: https:/doi.org/10.1101/2021.02 11.430775. this version posted March 3 2021. The copyright holder for this preprint (which was not certified by peer review) is the author/funder, who has granted bioRxiv a license to display the preprint in perpetuity. It is made available under aCC-BY-NC-ND 4.0 International license.

\section{Acknowledgements}

We would like to thank the support from our colleagues from the Teide-HPC Supercomputing facility (http://teidehpc.iter.es/en), which was funded by INP-2011-0063-PCT-430000-ACT (INNPLANTA program) from the Spanish Ministry of Economy and Competitiveness.

\section{Author Contributions}

Conceptualization, VGO, AMB, JMLS, CF; Data curation, VGO, AMB, JMLS, LARR, DJT, RGM; Methodology, VGO, AMB, JMLS, CZT, LARR, ADU, DJT, AIC, RGM; Supervision, CF; Writing-original draft preparation, VGO, AMB, CF; Writing-review and editing, VGO, AMB, JMLS, RGM, CF. All authors have read and agreed to the published version of the manuscript.

\section{Conflicts of Interest}

The authors declare no potential conflicts of interest with respect to the authorship and/or publication of this article. The funders had no role in the design of the study; in the collection, analyses, or interpretation of data; in the writing of the manuscript, or in the decision to publish the results.

\section{Funding}

This research was funded by Ministerio de Ciencia e Innovación (RTC-2017-6471-1; AEI/FEDER, UE), Fundación CajaCanarias and Fundación Bancaria "La Caixa" (2018PATRI20), co-financed by the European Regional Development Funds 'A way of making Europe' from the European Union; Cabildo Insular de Tenerife (CGIEU0000219140); and by the agreement OA17/008 with Instituto Tecnológico y de Energías Renovables (ITER) to strengthen scientific and technological education, training, research, development and innovation in Genomics, Personalized Medicine and Biotechnology. ADU was supported by a fellowship from the Spanish Ministry of Education and Vocational Training (grant number FPU16/01435). 


\section{References}

Abicht, A., Scharf, F., Kleinle, S., Schön, U., Holinski-Feder, E., Horvath, R., Benet-Pagès, A., \& Diebold, I. (2018). Mitochondrial and nuclear disease panel (Mito-aND-Panel): Combined sequencing of mitochondrial and nuclear DNA by a cost-effective and sensitive NGS-based method. Molecular Genetics \& Genomic Medicine, 6(6), 1188-1198.

Al-Nakeeb, K., Petersen, T. N., \& Sicheritz-Pontén, T. (2017). Norgal: extraction and de novo assembly of mitochondrial DNA from whole-genome sequencing data. BMC Bioinformatics, 18(1), 510.

Alonge, M., Soyk, S., Ramakrishnan, S., Wang, X., Goodwin, S., Sedlazeck, F. J., Lippman, Z. B., \& Schatz, M. C. (2019). RaGOO: fast and accurate reference-guided scaffolding of draft genomes. Genome Biology, 20(1), 224.

Amorim, A., Fernandes, T., \& Taveira, N. (2019). Mitochondrial DNA in human identification: a review. PeerJ, 7, e7314.

Anderson, S., Bankier, A. T., Barrell, B. G., de Bruijn, M. H., Coulson, A. R., Drouin, J., Eperon, I. C., Nierlich, D. P., Roe, B. A., Sanger, F., Schreier, P. H., Smith, A. J., Staden, R., \& Young, I. G. (1981). Sequence and organization of the human mitochondrial genome. Nature, 290(5806), 457-465.

Andrews, R. M., Kubacka, I., Chinnery, P. F., Lightowlers, R. N., Turnbull, D. M., \& Howell, N. (1999). Reanalysis and revision of the Cambridge reference sequence for human mitochondrial DNA. Nature Genetics, 23(2), 147.

Balter, M. (2011). Was North Africa the launch pad for modern human migrations? Science, 331(6013), $20-23$.

Bates, D., Mächler, M., Bolker, B., \& Walker, S. (2015). Fitting Linear Mixed-Effects Models Using Ime4. Journal of Statistical Software, Articles, 67(1), 1-48.

Beyter, D., Ingimundardottir, H., \& Eggertsson, H. P. (2019). Long read sequencing of 1,817 Icelanders provides insight into the role of structural variants in human disease. Biorxiv.

https://www.biorxiv.org/content/10.1101/848366v1.abstract

Børsting, C., \& Morling, N. (2015). Next generation sequencing and its applications in forensic genetics. Forensic Science International. Genetics, 18, 78-89.

Brotherton, P., Haak, W., Templeton, J., Brandt, G., Soubrier, J., Jane Adler, C., Richards, S. M., Der Sarkissian, C., Ganslmeier, R., Friederich, S., Dresely, V., van Oven, M., Kenyon, R., Van der Hoek, M. B., Korlach, J., Luong, K., Ho, S. Y. W., Quintana-Murci, L., Behar, D. M., ... Genographic Consortium. (2013). Neolithic 
mitochondrial haplogroup $\mathrm{H}$ genomes and the genetic origins of Europeans. Nature Communications, 4, 1764.

Calabrese, C., Simone, D., Diroma, M. A., Santorsola, M., Guttà, C., Gasparre, G., Picardi, E., Pesole, G., \& Attimonelli, M. (2014). MToolBox: a highly automated pipeline for heteroplasmy annotation and prioritization analysis of human mitochondrial variants in high-throughput sequencing. Bioinformatics, 30(21), 3115-3117.

Chan, E. K. F., Timmermann, A., Baldi, B. F., Moore, A. E., Lyons, R. J., Lee, S.-S., Kalsbeek, A. M. F., Petersen, D. C., Rautenbach, H., Förtsch, H. E. A., Bornman, M. S. R., \& Hayes, V. M. (2019). Human origins in a southern African palaeo-wetland and first migrations. Nature, 575(7781), 185-189.

Chung, Y., Rabe-Hesketh, S., Dorie, V., Gelman, A., \& Liu, J. (2013). A nondegenerate penalized likelihood estimator for variance parameters in multilevel models. Psychometrika, 78(4), 685-709.

Churchill, J. D., Stoljarova, M., King, J. L., \& Budowle, B. (2018). Massively parallel sequencing-enabled mixture analysis of mitochondrial DNA samples. International Journal of Legal Medicine, 132(5), 1263-1272.

Danecek, P., Auton, A., Abecasis, G., Albers, C. A., Banks, E., DePristo, M. A., Handsaker, R. E., Lunter, G., Marth, G. T., Sherry, S. T., McVean, G., Durbin, R., \& 1000 Genomes Project Analysis Group. (2011). The variant call format and VCFtools. Bioinformatics , 27(15), 2156-2158.

De Angelis, F., Scorrano, G., Martínez-Labarga, C., Scano, G., Macciardi, F., \& Rickards, O. (2018). Mitochondrial variability in the Mediterranean area: a complex stage for human migrations. Annals of Human Biology, 45(1), 5-19.

DeBalsi, K. L., Hoff, K. E., \& Copeland, W. C. (2017). Role of the mitochondrial DNA replication machinery in mitochondrial DNA mutagenesis, aging and age-related diseases. Ageing Research Reviews, 33, 89-104.

DePristo, M. A., Banks, E., Poplin, R., Garimella, K. V., Maguire, J. R., Hartl, C., Philippakis, A. A., del Angel, G., Rivas, M. A., Hanna, M., McKenna, A., Fennell, T. J., Kernytsky, A. M., Sivachenko, A. Y., Cibulskis, K., Gabriel, S. B., Altshuler, D., \& Daly, M. J. (2011). A framework for variation discovery and genotyping using next-generation DNA sequencing data. Nature Genetics, 43(5), 491-498.

Díaz-de Usera, A., Lorenzo-Salazar, J. M., Rubio-Rodríguez, L. A., Muñoz-Barrera, A., Guillen-Guio, B., Marcelino-Rodríguez, I., García-Olivares, V., Mendoza-Alvarez, A., Corrales, A., Ínigo-Campos, A., González-Montelongo, R., \& Flores, C. (2020). Evaluation of Whole-Exome Enrichment Solutions: Lessons from the High-End of the Short-Read Sequencing Scale. Journal of Clinical Medicine Research, 9(11), 
3656.

Diroma, M. A., Varvara, A. S., Attimonelli, M., Pesole, G., \& Picardi, E. (2020). Investigating Human

Mitochondrial Genomes in Single Cells. Genes, 11(5). https://doi.org/10.3390/genes11050534

Fan, L., \& Yao, Y.-G. (2011). MitoTool: a web server for the analysis and retrieval of human mitochondrial DNA sequence variations. Mitochondrion, 11(2), 351-356.

Fan, L., \& Yao, Y.-G. (2013). An update to MitoTool: using a new scoring system for faster mtDNA haplogroup determination. Mitochondrion, 13(4), 360-363.

Fox, J. (2003). Effect Displays in R for Generalised Linear Models. Journal of Statistical Software, 008(i15).

https://ideas.repec.org/a/jss/jstsof/v008i15.html

Franco-Sierra, N. D., \& Díaz-Nieto, J. F. (2020). Rapid mitochondrial genome sequencing based on Oxford

Nanopore Sequencing and a proxy for vertebrate species identification. Ecology and Evolution, 10(7), 3544-3560.

Fu, Q., Mittnik, A., Johnson, P. L. F., Bos, K., Lari, M., Bollongino, R., Sun, C., Giemsch, L., Schmitz, R., Burger, J., Ronchitelli, A. M., Martini, F., Cremonesi, R. G., Svoboda, J., Bauer, P., Caramelli, D., Castellano, S., Reich, D., Pääbo, S., \& Krause, J. (2013). A revised timescale for human evolution based on ancient mitochondrial genomes. Current Biology: $C B, 23(7)$, 553-559.

Gonder, M. K., Mortensen, H. M., Reed, F. A., de Sousa, A., \& Tishkoff, S. A. (2007). Whole-mtDNA genome sequence analysis of ancient African lineages. Molecular Biology and Evolution, 24(3), 757-768.

Griffin, H. R., Pyle, A., Blakely, E. L., Alston, C. L., Duff, J., Hudson, G., Horvath, R., Wilson, I. J., Santibanez-Koref, M., Taylor, R. W., \& Chinnery, P. F. (2014). Accurate mitochondrial DNA sequencing using off-target reads provides a single test to identify pathogenic point mutations. Genetics in Medicine: Official Journal of the American College of Medical Genetics, 16(12), 962-971.

Gurevich, A., Saveliev, V., Vyahhi, N., \& Tesler, G. (2013). QUAST: quality assessment tool for genome assemblies. Bioinformatics , 29(8), 1072-1075.

Hajdinjak, M., Fu, Q., Hübner, A., Petr, M., Mafessoni, F., Grote, S., Skoglund, P., Narasimham, V., Rougier, H., Crevecoeur, I., Semal, P., Soressi, M., Talamo, S., Hublin, J.-J., Gušić, I., Kućan, Ž., Rudan, P., Golovanova, L. V., Doronichev, V. B., ... Kelso, J. (2018). Reconstructing the genetic history of late Neanderthals. Nature, 555(7698), 652-656.

Hartig, F. (2017). DHARMa: residual diagnostics for hierarchical (multi-level/mixed) regression models. $R$ 
Package Version 0.1.

https://scholar.google.ca/scholar?cluster=4360617861234309959,11567242814940452891,2963838797

$944146284,13693552109982088139,10858470353899442396,13508535809485820766,8264605584777$

$647235,11449340219754401872,4568553816172706093,7031840379694243239,805624554589352998$

$6,5011821598121647820 \& h l=e n \& a s \_s d t=0,5 \& s c i o d t=0,5$

Heinze, G., \& Schemper, M. (2002). A solution to the problem of separation in logistic regression. Statistics in Medicine, 21(16), 2409-2419.

Hothorn, T., Bretz, F., \& Westfall, P. (2008). Simultaneous inference in general parametric models. Biometrical Journal. Biometrische Zeitschrift, 50(3), 346-363.

Ishiya, K., \& Ueda, S. (2017). MitoSuite: a graphical tool for human mitochondrial genome profiling in massive parallel sequencing. PeerJ, 5, e3406.

Ishiya, K., \& Ueda, S. (2019). Novel approach for accurate detection of contaminating human mitochondrial DNA in next-generation sequencing data - IOPscience. iopscience.iop.org. https://iopscience.iop.org/article/10.1088/1742-6596/1391/1/012045/meta

Jagadeesan, A., Ebenesersdóttir, S. S., Guðmundsdóttir, V. B., Thordardottir, E. L., Moore, K. H. S., \& Helgason, A. (2020). HaploGrouper: A generalized approach to haplogroup classification. Bioinformatics . https://doi.org/10.1093/bioinformatics/btaa729

Jennings, L. J., Arcila, M. E., Corless, C., Kamel-Reid, S., Lubin, I. M., Pfeifer, J., Temple-Smolkin, R. L., Voelkerding, K. V., \& Nikiforova, M. N. (2017). Guidelines for Validation of Next-Generation SequencingBased Oncology Panels: A Joint Consensus Recommendation of the Association for Molecular Pathology and College of American Pathologists. The Journal of Molecular Diagnostics: JMD, 19(3), 341-365.

Just, R. S., Leney, M. D., Barritt, S. M., Los, C. W., Smith, B. C., Holland, T. D., \& Parsons, T. J. (2009). The use of mitochondrial DNA single nucleotide polymorphisms to assist in the resolution of three challenging forensic cases. Journal of Forensic Sciences, 54(4), 887-891.

Kim, K., Kim, Y., Kim, D.-H., Kwon, C., \& Kim, K.-Y. (2020). Haplotracker: a web application for simple and accurate mitochondrial haplogrouping using short DNA fragments. In bioRxiv (p. 2020.04.23.057646). https://doi.org/10.1101/2020.04.23.057646

Lee, H. Y., Song, I., Ha, E., Cho, S.-B., Yang, W. I., \& Shin, K.-J. (2008). mtDNAmanager: a Web-based tool for the management and quality analysis of mitochondrial DNA control-region sequences. BMC Bioinformatics, 


\section{9, 483.}

Leger, A., \& Leonardi, T. (2019). pycoQC, interactive quality control for Oxford Nanopore Sequencing. Journal of Open Source Software, 4(34), 1236.

Li, H. (2016). Minimap and miniasm: fast mapping and de novo assembly for noisy long sequences. Bioinformatics , 32(14), 2103-2110.

Li, H. (2018). Minimap2: pairwise alignment for nucleotide sequences. Bioinformatics , 34(18), 3094-3100.

Lindberg, M. R., Schmedes, S. E., Hewitt, F. C., Haas, J. L., Ternus, K. L., Kadavy, D. R., \& Budowle, B. (2016). A Comparison and Integration of MiSeq and MinION Platforms for Sequencing Single Source and Mixed Mitochondrial Genomes. PloS One, 11(12), e0167600.

Llamas, B., Fehren-Schmitz, L., Valverde, G., Soubrier, J., Mallick, S., Rohland, N., Nordenfelt, S., Valdiosera, C., Richards, S. M., Rohrlach, A., Romero, M. I. B., Espinoza, I. F., Cagigao, E. T., Jiménez, L. W., Makowski, K., Reyna, I. S. L., Lory, J. M., Torrez, J. A. B., Rivera, M. A., ... Haak, W. (2016). Ancient mitochondrial DNA provides high-resolution time scale of the peopling of the Americas. Science Advances, 2(4), e1501385.

Maca-Meyer, N., González, A. M., Larruga, J. M., Flores, C., \& Cabrera, V. M. (2001). Major genomic mitochondrial lineages delineate early human expansions. BMC Genetics, 2, 13.

McKenna, A., Hanna, M., Banks, E., Sivachenko, A., Cibulskis, K., Kernytsky, A., Garimella, K., Altshuler, D., Gabriel, S., Daly, M., \& DePristo, M. A. (2010). The Genome Analysis Toolkit: a MapReduce framework for analyzing next-generation DNA sequencing data. Genome Research, 20(9), 1297-1303.

Navarro-Gomez, D., Leipzig, J., Shen, L., Lott, M., Stassen, A. P. M., Wallace, D. C., Wiggs, J. L., Falk, M. J., van Oven, M., \& Gai, X. (2015). Phy-Mer: a novel alignment-free and reference-independent mitochondrial haplogroup classifier. Bioinformatics , 31(8), 1310-1312.

Olson, N. D., Wagner, J., McDaniel, J., Stephens, S. H., Westreich, S. T., Prasanna, A. G., Johanson, E., Boja, E., Maier, E. J., Serang, O., Jáspez, D., Lorenzo-Salazar, J. M., Muñoz-Barrera, A., Rubio-Rodríguez, L. A., Flores, C., Kyriakidis, K., Malousi, A., Shafin, K., Pesout, T., ... Zook, J. M. (2020). precisionFDA Truth Challenge V2: Calling variants from short- and long-reads in difficult-to-map regions. Biorxiv. https://doi.org/10.1101/2020.11.13.380741

Parson, W., \& Dür, A. (2007). EMPOP-A forensic mtDNA database. Forensic Science International. Genetics, $1(2), 88-92$.

Parson, W., Gusmão, L., Hares, D. R., Irwin, J. A., Mayr, W. R., Morling, N., Pokorak, E., Prinz, M., Salas, A., 
bioRxiv preprint doi: https://doi org/10.1101/2021.02 11.430775. this version posted March 3, 2021. The copyright holder for this preprint (which was not certified by peer review) is the author/funder, who has granted bioRxiv a license to display the preprint in perpetuity. It is made available under aCC-BY-NC-ND 4.0 International license.

Schneider, P. M., Parsons, T. J., \& DNA Commission of the International Society for Forensic Genetics.

(2014). DNA Commission of the International Society for Forensic Genetics: revised and extended guidelines for mitochondrial DNA typing. Forensic Science International. Genetics, 13, 134-142.

Patowary, A., Nesbitt, R., Archer, M., Bernier, R., \& Brkanac, Z. (2017). Next Generation Sequencing Mitochondrial DNA Analysis in Autism Spectrum Disorder. Autism Research: Official Journal of the International Society for Autism Research, 10(8), 1338-1343.

Petrackova, A., Vasinek, M., Sedlarikova, L., Dyskova, T., Schneiderova, P., Novosad, T., Papajik, T., \& Kriegova, E. (2019). Standardization of Sequencing Coverage Depth in NGS: Recommendation for Detection of Clonal and Subclonal Mutations in Cancer Diagnostics. Frontiers in Oncology, 9, 851.

Picardi, E., \& Pesole, G. (2012). Mitochondrial genomes gleaned from human whole-exome sequencing. Nature Methods, 9(6), 523-524.

Posth, C., Renaud, G., Mittnik, A., Drucker, D. G., Rougier, H., Cupillard, C., Valentin, F., Thevenet, C., Furtwängler, A., Wißing, C., Francken, M., Malina, M., Bolus, M., Lari, M., Gigli, E., Capecchi, G., Crevecoeur, I., Beauval, C., Flas, D., ... Krause, J. (2016). Pleistocene Mitochondrial Genomes Suggest a Single Major Dispersal of Non-Africans and a Late Glacial Population Turnover in Europe. Current Biology: $C B, 26(6), 827-833$.

Puttick, C., Kumar, K. R., Davis, R. L., Pinese, M., Thomas, D. M., Dinger, M. E., Sue, C. M., \& Cowley, M. J. (2019). mity: A highly sensitive mitochondrial variant analysis pipeline for whole genome sequencing data. In Bioinformatics (No. biorxiv;852210v1). bioRxiv. https://doi.org/10.1101/852210

Pyle, A., Anugrha, H., Kurzawa-Akanbi, M., Yarnall, A., Burn, D., \& Hudson, G. (2016). Reduced mitochondrial DNA copy number is a biomarker of Parkinson's disease. Neurobiology of Aging, 38, 216.e7-e216.e10. Raymond, F. L., Horvath, R., \& Chinnery, P. F. (2018). First-line genomic diagnosis of mitochondrial disorders [Review of First-line genomic diagnosis of mitochondrial disorders]. Nature Reviews. Genetics, 19(7), 399-400. nature.com.

Robin, E. D., \& Wong, R. (1988). Mitochondrial DNA molecules and virtual number of mitochondria per cell in mammalian cells. Journal of Cellular Physiology, 136(3), 507-513.

Röck, A. W., Dür, A., van Oven, M., \& Parson, W. (2013). Concept for estimating mitochondrial DNA haplogroups using a maximum likelihood approach (EMMA). Forensic Science International. Genetics, 7(6), 601-609. 
bioRxiv preprint doi: https:/doi.org/10.1101/2021.02 11.430775. this version posted March 3 2021. The copyright holder for this preprint (which was not certified by peer review) is the author/funder, who has granted bioRxiv a license to display the preprint in perpetuity. It is made available under aCC-BY-NC-ND 4.0 International license.

Schönberg, A., Theunert, C., Li, M., Stoneking, M., \& Nasidze, I. (2011). High-throughput sequencing of complete human mtDNA genomes from the Caucasus and West Asia: high diversity and demographic inferences. European Journal of Human Genetics: EJHG, 19(9), 988-994.

Smieszek, S., Mitchell, S. L., Farber-Eger, E. H., Veatch, O. J., Wheeler, N. R., Goodloe, R. J., Wells, Q. S., Murdock, D. G., \& Crawford, D. C. (2018). Hi-MC: a novel method for high-throughput mitochondrial haplogroup classification. PeerJ, 6, e5149.

Sosa, M. X., Sivakumar, I. K. A., Maragh, S., Veeramachaneni, V., Hariharan, R., Parulekar, M., Fredrikson, K. M., Harkins, T. T., Lin, J., Feldman, A. B., Tata, P., Ehret, G. B., \& Chakravarti, A. (2012). Next-generation sequencing of human mitochondrial reference genomes uncovers high heteroplasmy frequency. PLoS Computational Biology, 8(10), e1002737.

van Oven, M., \& Kayser, M. (2009). Updated comprehensive phylogenetic tree of global human mitochondrial DNA variation. Human Mutation, 30(2), E386-E394.

Vaser, R., Sović, I., Nagarajan, N., \& Šikić, M. (2017). Fast and accurate de novo genome assembly from long uncorrected reads. Genome Research, 27(5), 737-746.

Vasta, V., Ng, S. B., Turner, E. H., Shendure, J., \& Hahn, S. H. (2009). Next generation sequence analysis for mitochondrial disorders. Genome Medicine, 1(10), 100.

Vianello, D., Sevini, F., Castellani, G., Lomartire, L., Capri, M., \& Franceschi, C. (2013). HAPLOFIND: a new method for high-throughput mtDNA haplogroup assignment. Human Mutation, 34(9), 1189-1194.

Vohr, S. H., Gordon, R., Eizenga, J. M., Erlich, H. A., Calloway, C. D., \& Green, R. E. (2017). A phylogenetic approach for haplotype analysis of sequence data from complex mitochondrial mixtures. Forensic Science International. Genetics, 30, 93-105.

Watson, E., Davis, R., \& Sue, C. M. (2020). New diagnostic pathways for mitochondrial disease. Journal of Translational Genetics and Genomics. https://doi.org/10.20517/jtgg.2020.31

Weissensteiner, H., Forer, L., Fendt, L., Kheirkhah, A., Salas, A., Kronenberg, F., \& Schoenherr, S. (2020). Haplocheck: Phylogeny-based Contamination Detection in Mitochondrial and Whole-Genome Sequencing Studies. In bioRxiv (p. 2020.05.06.080952). https://doi.org/10.1101/2020.05.06.080952

Weissensteiner, H., Pacher, D., Kloss-Brandstätter, A., Forer, L., Specht, G., Bandelt, H.-J., Kronenberg, F., Salas, A., \& Schönherr, S. (2016). HaploGrep 2: mitochondrial haplogroup classification in the era of highthroughput sequencing. Nucleic Acids Research, 44(W1), W58-W63. 
30775. this version posted March 32021 The copvriaht holder for this preprint (which was not certified by peer review) is the author/funder, who has granted bioRxiv a license to display the preprint in perpetuity. It is made available under aCC-BY-NC-ND 4.0 International license.

West, A. P., \& Shadel, G. S. (2017). Mitochondrial DNA in innate immune responses and inflammatory pathology. Nature Reviews. Immunology, 17(6), 363-375.

Wickham, H. (2016). ggplot2: Elegant Graphics for Data Analysis. Springer.

Wick, R. R., Judd, L. M., Gorrie, C. L., \& Holt, K. E. (2017). Unicycler: Resolving bacterial genome assemblies from short and long sequencing reads. PLoS Computational Biology, 13(6), e1005595.

Wortmann, S. B., Koolen, D. A., Smeitink, J. A., van den Heuvel, L., \& Rodenburg, R. J. (2015). Whole exome sequencing of suspected mitochondrial patients in clinical practice. Journal of Inherited Metabolic Disease, 38(3), 437-443.

Yin, C., Liu, Y., Guo, X., Li, D., Fang, W., Yang, J., Zhou, F., Niu, W., Jia, Y., Yang, H., \& Xing, J. (2019). An Effective Strategy to Eliminate Inherent Cross-Contamination in mtDNA Next-Generation Sequencing of Multiple Samples. The Journal of Molecular Diagnostics: JMD, 21(4), 593-601. 